(W)

Check for

updates

Cite as

Nano-Micro Lett.

(2021) 13:184

Received: 28 May 2021

Accepted: 3 August 2021

Published online: 31 August 2021

(C) The Author(s) 2021

\section{Laser Erasing and Rewriting of Flexible Copper Circuits}

\author{
Xingwen Zhou ${ }^{1}$, Wei Guo ${ }^{1}$, Peng Peng ${ }^{2} \bowtie$
}

\title{
HIGHLIGHTS
}

- An up-bottom laser erasing process utilizing electrochemical corrosion has been integrated into the bottom-up writing process.

- The presented erased laser writing technology exhibits excellent reproducibility for sustainable manufacturing of flexible highly conductive $\mathrm{Cu}$ structure.

- The suitability of the writing-erasing-rewriting process for repairing failure patterns and reconfiguring circuits has been demonstrated.

\begin{abstract}
Integrating construction and reconstruction of highly conductive structures into one process is of great interest in developing and manufacturing of electronics, but it is quite challenging because these two involve contradictive additive and subtractive processes. In this work, we report an all-laser mask-less processing technology that integrates manufacturing, modifying, and restoring of highly conductive $\mathrm{Cu}$ structures. By traveling a focused laser, the $\mathrm{Cu}$ patterns can be fabricated on the flexible substrate, while these as-written patterns can be selectively erased by changing the laser to a defocused state. Subsequently, the fresh patterns with identical conductivity and stabil-
\end{abstract} ity can be rewritten by repeating the writing step. Further, this eras-

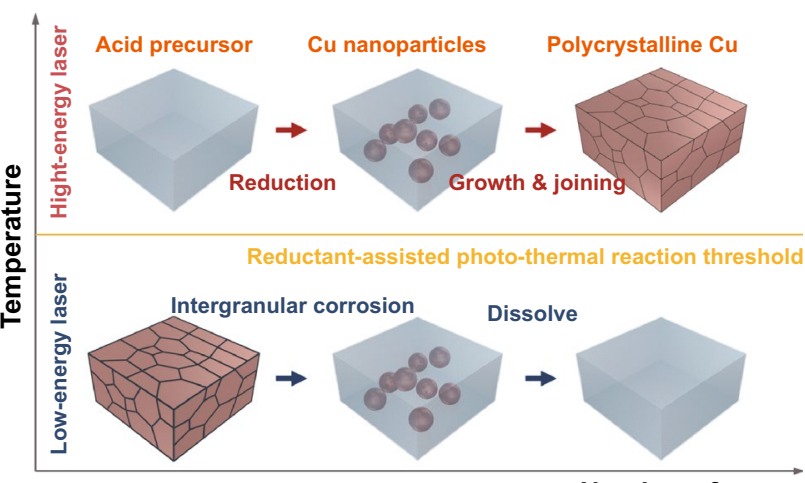

Number of scans ing-rewriting process is also capable of repairing failure patterns, such as oxidation and cracking. Owing to the high controllability of this writing-erasing-rewriting process and its excellent reproducibility for conductive structures, it opens a new avenue for rapid healing and prototyping of electronics.

KEYWORDS Laser writing; Laser erasing; Copper electrodes; Electronic repairing; Flexible electronics

Peng Peng, peng.peng@uwaterloo.ca

1 School of Mechanical Engineering and Automation, Beihang University, Beijing 100191, People's Republic of China

2 Department of Mechanical and Mechatronics Engineering, Centre for Advanced Materials Joining, University of Waterloo, Waterloo, ON N2L 3G1, Canada 


\section{Introduction}

Flexible electronics are indispensable in the fields of healthcare, human-computer interaction, environmental monitoring, artificial intelligence, and energy management $[1,2]$. The conductive component is the core part of these electronics as it electrically connects the other electronic components to guarantee the power and signal transmitting in systems [3,4]. Emerging nanostructured materials open a new avenue for the design and fabrication of these components [4]. The novel efficient manufacturing technologies of conductive structures promote the rapid emerging of high-performance electronics, including various sensors [5-7], energy devices [8-10], and even integrated devices [11-13].

Undoubtedly, prototyping of electronic products is essential for optimizing their performance during the development process [14]. In this process, constant transform of conductive paths is inevitable to adapt to the modified electrical circuits. Reprogramming these circuits in an integrated flexible electronic generally is unrealistic due to a highly integrating of components, resulting in the scrapping of them as defective products. Furthermore, batch-produced electronic failures related to the conductive components are also ubiquitous in the production and service process. Abandonment products in these above processes, together with that have reached the end of economic life [15], result in the generation of electronic waste. Electronic waste management is uneconomical and complicated, and it has arisen a rapidly growing pollution problem worldwide [16, 17]. Therefore, developing an efficient technology suitable for flexible electronics restoring is in high demand.

Reversible laser processing of nanostructured materials is expected to be an alternative solution to this proposition because it integrates the construction and reconstruction processes, which has recently attracted considerable interest in information storage, dynamic coloration, and reprogrammable functional resistance manufacturing [18-22]. The basic principle of these techniques is based on the interconversion of nanostructured metals and oxides, which can be controlled by varying the process parameters such as atmosphere, laser parameters, laser type, and precursor composition [19-22]. However, manufacturing highly conductive components with these methods is rarely reported, probably because these reversible structures' conductivity is not satisfactory. Although with the assistance of reducing agents, a photothermal chemical reduction can selectively reduce oxidized conductive structures to restore their electrical conductivity; this process is only suitable for the nanomaterials with high specific surface area (such as nanowires) [23, 24]. This suggests that the process is based on the material prepared by complex pre-synthesis technologies, and the conductivity of the obtained structures still can be further improved because of their porosity.

Here, we introduce an all-laser processing technology that utilizes the interaction of the laser and a low-cost liquid precursor to write, erase, and rewrite the highly conductive $\mathrm{Cu}$ patterns on the flexible substrate. The structural evolution during processing and the underlying mechanism of laser erasing is investigated. The erasing process can selectively remove the partial or complete written structure to restore the substrate to a near-initial state, which is also capable of repairing the oxidized or cracked failure structures. The similar electrical performance and stability between the written and rewritten patterns can be achieved. Because the construction and removal of $\mathrm{Cu}$ patterns can be dynamically switched via adjusting the laser parameters during processing; the application of this technology in the prototyping of electronics is also demonstrated.

\section{Experimental}

\subsection{Precursor Preparation and Laser Processing}

In a typical procedure for preparing the $\mathrm{Cu}$ ionic precursor, copper nitrate trihydrate $\left(\mathrm{Cu}\left(\mathrm{NO}_{3}\right)_{2} \cdot 3 \mathrm{H}_{2} \mathrm{O}\right)$ was dissolved in N-Methyl pyrrolidone (NMP) solution $\left(3 \mathrm{~mol} \mathrm{~L}^{-1}\right)$ and then mixed with ethylene glycol (EG) at a volume ratio of 10:1. Before laser processing, the $200 \mu \mathrm{m}$-thick polyimide (PI) and $1 \mathrm{~mm}$-thick glass substrates were washed and hydrophilized with $\mathrm{O}_{2}$-plasma. Subsequently, $600 \mu \mathrm{L}$ of the precursor was covered on the desired region of substrate $(25 \times 50 \mathrm{~mm}$, Fig. S1). A continuous diode laser system (BWT Beijing Ltd) of a wavelength of $808 \mathrm{~nm}$ was used as a laser source for processing. All the laser processing was performed under ambient conditions with a 
constant scanning velocity of $10 \mathrm{~mm} \mathrm{~s}^{-1}$. The laser power used for writing and erasing was set to 4.7 and $2.7 \mathrm{~W}$, respectively. An objective lens $(4 \times)$ was used to focus the laser beam to around $650 \mu \mathrm{m}$ (measured using standard photographic paper) for writing. Defocus of laser in erasing was achieved by adjusting the distance between the objective lens and the substrate.

\subsection{Material Characterization}

UV-vis spectra of the liquid precursors were determined using a UV-vis spectrometer (Cary 5000, USA Varian). Viscosity of the precursor was characterized using a rheometer (MCR92, Anton Paar) at room temperature $\left(\sim 25^{\circ} \mathrm{C}\right)$. Differential scanning calorimetry and thermal gravimetric analysis (DSC-TGA) of the precursor were carried out with a SDT Q600 thermal analyzer with a heating rate of $10{ }^{\circ} \mathrm{C} \mathrm{min}-1$ under air atmosphere. The microstructure and morphology of the patterns were characterized by optical microscope (OM, Zeiss Scope.A1), field emission scanning electron microscopy (FESEM, Merlin Compact), and transmission electron microscopy (TEM, JEOL 2100). Crystal structures were measured by an X-ray diffraction (XRD, $\mathrm{Cu} \mathrm{K} \alpha$ radiation, D8-Advance, Bruker, USA). X-ray photoelectron spectroscopy (XPS, K-Alpha, ULVAC-PHI PHI-5000 VPIII, Japan) in conjunction with $\mathrm{Ar}^{+}$-ion sputtering was used to characterize the approximate element composition of the surface as a function of depth. All the XPS spectra were corrected using the C $1 \mathrm{~s}$ peaks $(284.8 \mathrm{eV})$ as reference. Electrochemical test was performed on an electrochemical workstation $(\mathrm{CHI} 660 \mathrm{E}, \mathrm{CH}$ Instruments, Shanghai) in a $\mathrm{HNO}_{3}$ solution $(\mathrm{pH}=2.5)$ using the written patterns as working electrode. The commercial platinum foil $(2.5 \times 4 \mathrm{~mm})$ and $\mathrm{Ag} / \mathrm{AgCl}$ (saturated $\mathrm{KCl})$ electrode were used as counter electrode and reference electrode, respectively. The $\mathrm{pH}$ values of the solutions were measured by pH meter (PHB-4, INESA, Shanghai) with E-201F electrode.

\subsection{Electrical Performance, Mechanical Stability, and Thermal Stability Tests}

All the electrical performances were carried by a Keithley 2400 source-meter. The bending performance of the fabricated pattern was performed using a two-axis platform with a controllable velocity. The experimental setup was established by moving one end, while the other end was fixed. The in situ resistance change of pattern during bending was monitored by connecting additional wrapping wires at the ends of patterns. The adhesion test of patterns was performed based on a tape peeling test; $3 \mathrm{M}$ tape was pressed onto the top of the patterns and then manually torn off. The thermal stability was conducted in a conventional oven with a controllable temperature environment.

\section{Results and Discussion}

Figure 1a illustrates a schematic of the proposed laser writing-erasing-rewriting technology, in which all the processes are performed by irradiating a traveled laser on the substrate covered with a liquid $\mathrm{Cu}$ salt precursor. The $\mathrm{Cu}$ pattern is fabricated by scanning a focused laser at the desired area, while the written pattern can be selectively erased by irradiating a defocused laser. Subsequently, the writing process can be executed again with the focused laser to fabricate a new $\mathrm{Cu}$ pattern. Figure $1 \mathrm{~b}$ demonstrates this writing and erasing processes on a commercial PI substrate. An Archimedean spiral $\mathrm{Cu}$ pattern is first written by scanning the focused laser (Fig. 1b-i), and part of this pattern is then erased by scanning with a defocused laser (Fig. 1bii). Figure 1b-iii shows SEM and EDS characterizations of the interface between written and erased regions. The pattern and corresponding $\mathrm{Cu}$ element are invisible in the erased region, while it still exists intact in the written region, confirming the excellent selectivity of the erasing process. There is no doubt that the written pattern can be fully erased via controlling the defocused laser trajectory. By replacing the precursor after each writing-erasing cycle, the rewriting process can be multiple performed, as demonstrated by the sequential patterning of "A-D" letters on the same area of the PI substrate (Fig. 1c). Only the current letter can be observed at this region, indicating the previous pattern has been completely removed after each erasing cycle. The similar morphologies and lusters of these patterns confirm the good reproducibility of the rewriting process, also suggesting negligible damage to the substrate of these multiple erasing-rewriting cycles.

The used precursor is a modified solution from our previous study [9], which is a low-cost solution consisting of $\mathrm{Cu}\left(\mathrm{NO}_{3}\right)_{2} \cdot 3 \mathrm{H}_{2} \mathrm{O}$ and EG dissolved in NMP. The viscosity of the precursor in the range of $10-100 \mathrm{~s}^{-1}$ is constant at $225.2 \mathrm{mPa}$ s, indicating it is a Newtonian liquid with ideally 

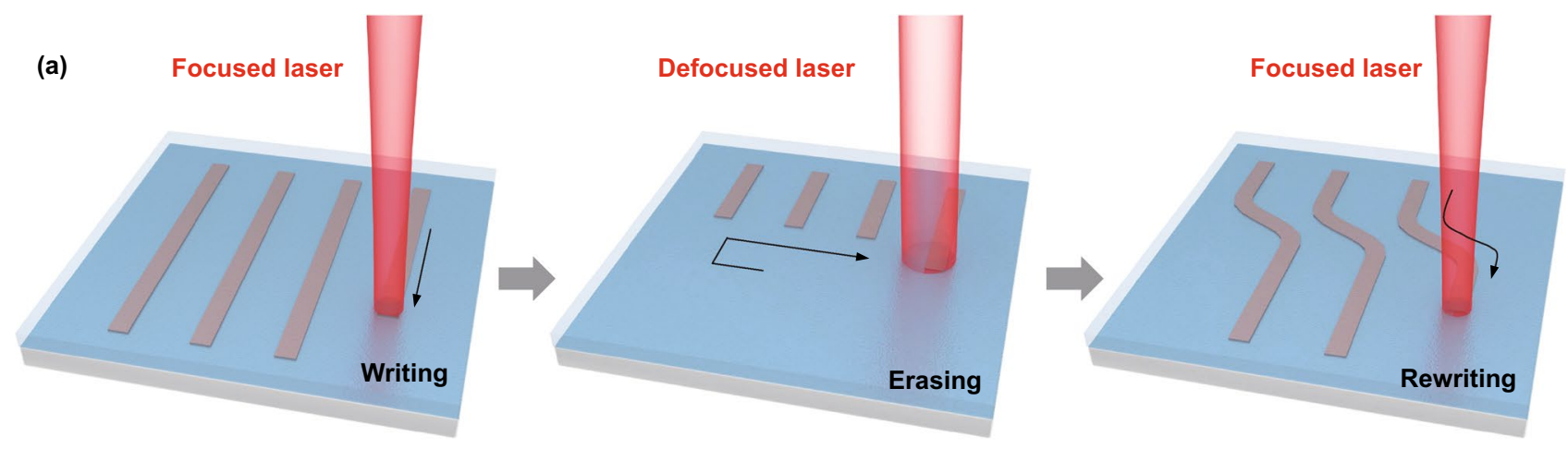

Liquid precursor

Cu pattern Substrate
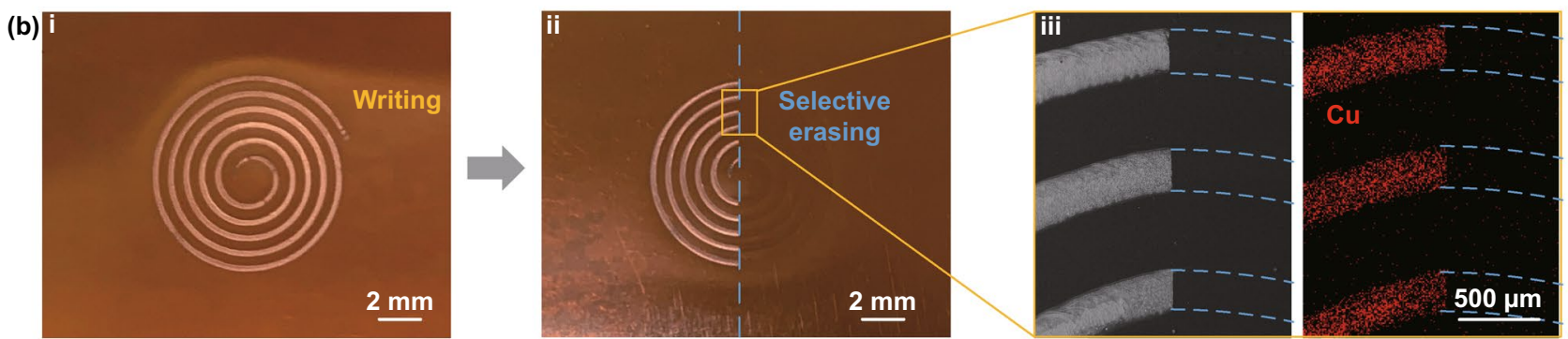

(c)

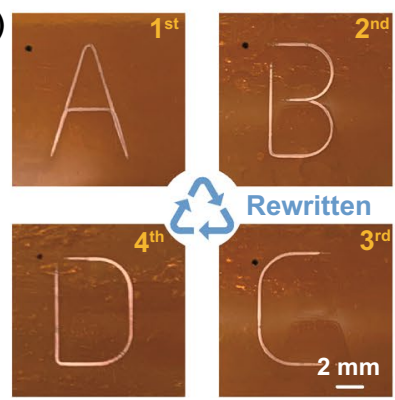

(d)

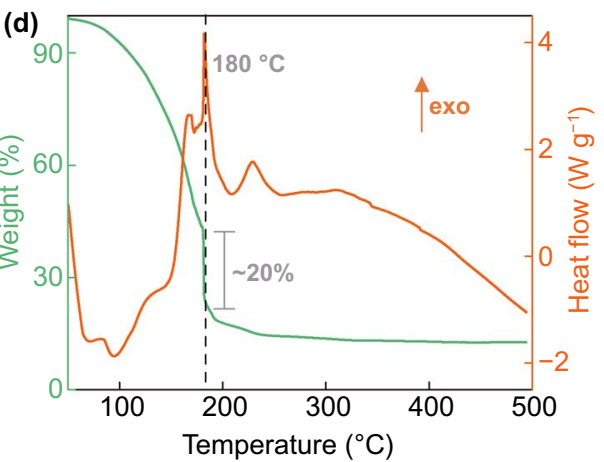

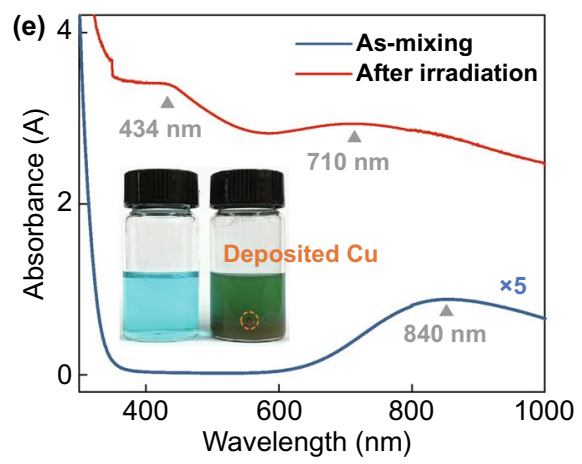

Fig. 1 Demonstration of erasable laser writing process and the precursor characterization. a Schematic of the all-laser writing-erasing-rewriting process. b Characterization of the pattern during writing-erasing process. Digital photos of the (i) as-written pattern (ii) after selective erasing, and (iii) SEM and EDS images. c Letters successively written and erased at a same region on the substrate. The black dot is a deliberate mark for this region. d DSC and TGA curves of the precursor. e UV-vis spectra of the precursor (diluted to 1/200 using EG) before and after laser irradiation. Inset photos show the solution change after irradiation, whereof the dotted circle marks the deposited $\mathrm{Cu}$ on the glass bottle

viscous. Figure 1d plots the DSC-TGA curves of the precursor. As seen, the endothermic peaks at around 202 and $87^{\circ} \mathrm{C}$ are, respectively, attributed to the evaporation of NMP and water from $\mathrm{Cu}\left(\mathrm{NO}_{3}\right)_{2} \cdot 3 \mathrm{H}_{2} \mathrm{O}[25,26]$, while the exothermic peak at around $212{ }^{\circ} \mathrm{C}$ is related to the decomposition of $\mathrm{Cu}\left(\mathrm{NO}_{3}\right)_{2}$ [26]. Importantly, the peaks at around $180^{\circ} \mathrm{C}$ (with a range from 140 to $200{ }^{\circ} \mathrm{C}$ ) is identified in the DSC curve, which agrees to the decomposition temperature of EG [27, 28]. Correspondingly, an obviously mass loss of about $20 \%$ is observed in the TGA curve, suggesting the formation of $\mathrm{Cu}$ structures [24, 29]. It can be considered that thermal decomposition of the reducing agent accounts for the $\mathrm{Cu}^{2+}$ reduction to assist the laser writing process. The polyol reduction mechanism can be summarized as [24, 30]:

$2 \mathrm{HO}\left(\mathrm{CH}_{2}\right)_{2} \stackrel{\text { (heat) }-2 \mathrm{H}_{2} \mathrm{O}}{\longrightarrow} 2 \mathrm{C}_{2} \mathrm{H}_{4} \mathrm{O} \stackrel{\mathrm{Cu}(\mathrm{II})}{\longrightarrow} \mathrm{C}_{4} \mathrm{H}_{6} \mathrm{O}_{2}+\mathrm{H}_{2} \mathrm{O}+\mathrm{Cu}$

As the precursor can absorb laser in near-infrared wavelength range around $840 \mathrm{~nm}$ (Fig. 1e), irradiating with a laser in the corresponding wavelength range ( $808 \mathrm{~nm}$ laser used in this work) can directly heat the precursor. This also allows a wider selection of substrates for processing (for 
example the glass substrate, see Fig. S2). Infrared imaging indicates the region around laser spot can be higher than $180{ }^{\circ} \mathrm{C}$ during irradiating, while it is only around $120{ }^{\circ} \mathrm{C}$ in the solution bulk (for detailed information, see Fig. S3). After irradiating, a thin $\mathrm{Cu}$ layer will be deposited on the inner wall of the glass bottle while the color of solution turns from blue to dark green (as marked in inset of Fig. 1e). The UV-vis spectrum indicates the absorbance of precursor obviously increases after laser irradiating, and two peaks at 434 and $710 \mathrm{~nm}$ can be observed. The former one closes to the intrinsic bandgap absorption of $\mathrm{Cu}_{2} \mathrm{O}[31,32]$, while the latter one may be assignable to the transformation of $\mathrm{Cu}^{2+}$ complexes [33, 34]. This confirms that the amount of $\mathrm{Cu}$ formed in the solution bulk is almost negligible due to the insufficient temperature (also can be verified by the XRD analysis, see Fig. S4). These results indicate the laser irradiation will only cause a local temperature rise if the processing is performed on a target substrate, which is beneficial to avoid global thermal damage to the flexible substrate (the effects of substrate on the thermal accumulation have been discussed in supporting information, see Fig. S5).
According to our previous study [9], the resistivity of the written pattern can reach an excellent value only $~ 2.5$ times that of bulk $\mathrm{Cu}$ (around $4 \times 10^{-8} \Omega \mathrm{m}$ ), which is superior to the previously reported flexible structure obtained by one-step laser writing. Here, the writing parameters are further optimized to improve the writing efficiency (for detail parametric study, see Section S3 in Supporting Information), which can fabricate the pattern with a similar order of magnitude as bulk $\mathrm{Cu}$ after five laser scans (labeled as $N_{\mathrm{w}}$ ). Figure 2a plots the Cu LMM spectra of the typical pattern at different sputter depths. A peak at $916.8 \mathrm{eV}$ [35] is identified on the surface, indicating the chemical state of $\mathrm{Cu}$ on the surface is mainly of $\mathrm{Cu}_{2} \mathrm{O}$. Increasing the sputter depth larger than $\sim 5 \mathrm{~nm}$, only the $\mathrm{Cu}$ peak at around $918.6 \mathrm{eV}$ [35] can be observed. The peak position is constant with further increasing the sputter depth, confirming the $\mathrm{Cu}_{2} \mathrm{O}$ only present within $\sim 5 \mathrm{~nm}$ near the pattern surface (for atomic concentration at different sputter depth, Fig. S8). Obviously, high $\mathrm{Cu}$ content and dense structure of pattern (inset in Fig. 2a) account for its excellent conductivity.
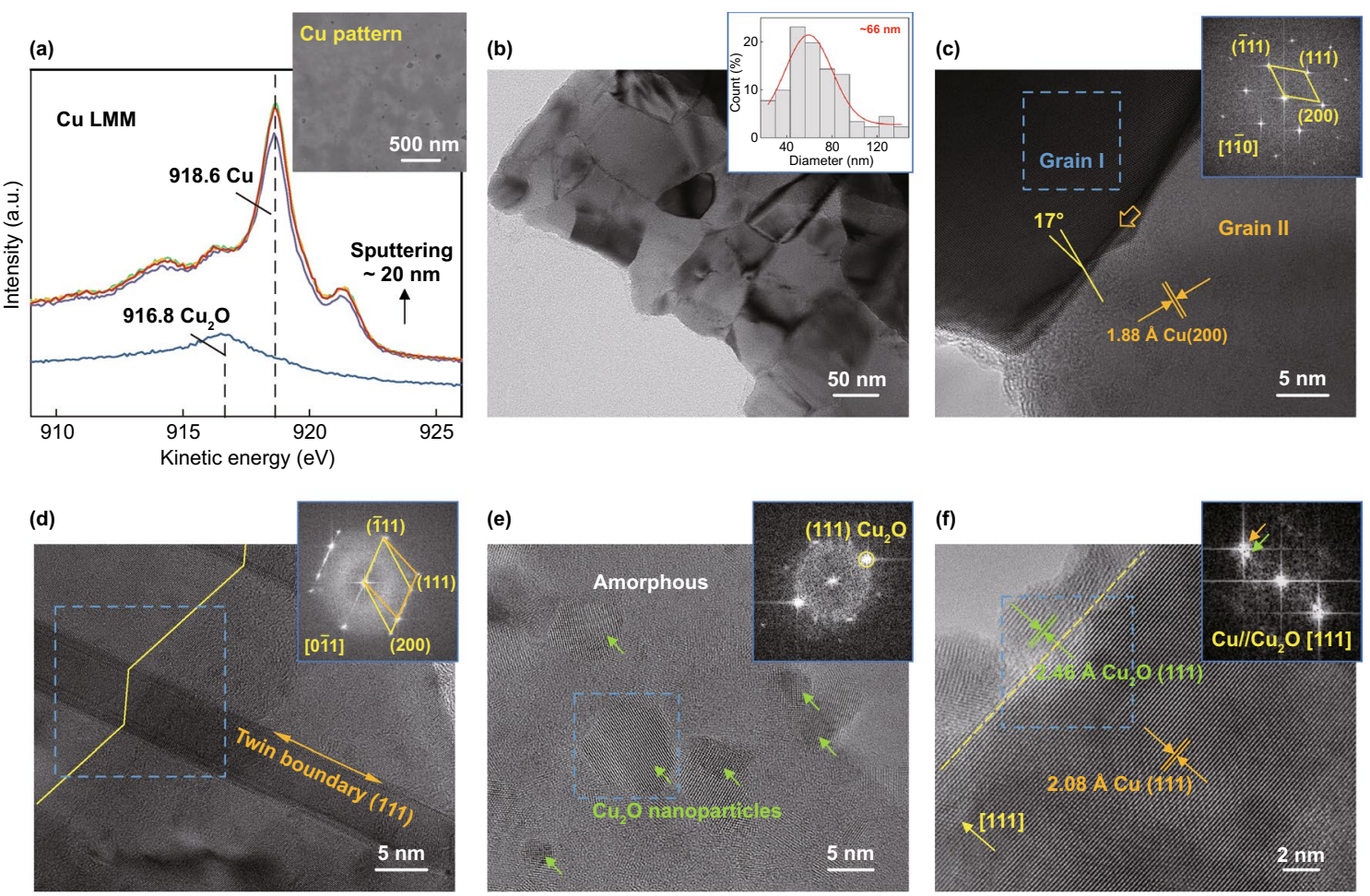

Fig. 2 Characterization of the typical written pattern. a Cu LMM spectra of the pattern obtained at $10 N_{\mathrm{w}}$ as a function of the sputter depth. Inset SEM image shows the morphology of the typical pattern. TEM images of the $\mathbf{b}-\mathbf{d}$ typical dense $\mathrm{Cu}$ and $\mathbf{e}-\mathbf{f} \mathrm{Cu}_{2} \mathrm{O}$ structures in the pattern. Inset image in b is the statistics of the particle size. Insets in $\mathbf{c}-\mathbf{f}$ are the FFT images corresponding to the regions marked by the blue dotted boxes 
The crystallographic characteristics of pattern are further analyzed by TEM observation. The obtained pattern mainly consists of a dense sintered polycrystalline structure with an average grain size of $66 \mathrm{~nm}$ (Fig. 2b). High-resolution TEM observation indicates these single crystalline grains are with a clear lattice spacing of $0.208 \mathrm{~nm}$ corresponding to the (111) plane of cubic $\mathrm{Cu}$, which also can be verified by the fast Fourier transform (FFT) analysis (Fig. 2c). These grains are mainly interconnected via random boundaries, such as a high angle boundary with a misorientation angle of about $17^{\circ}$. The $\Sigma 3$ boundaries (growth twins parallel to each other in $\{111\}$ planes with the semi-coherent interface) are also identified (Fig. 2d), which are common in the epitaxially joined cubic nanostructures due to their low stacking-fault energy [36, 37]. Pulsed thermal cycle associating with multiple laser scans limits the grain size in nanometers because instantaneous high-energy input is beneficial to promote the formation of nucleation sites, while rapid cooling promptly interrupts grain growth and facilitates the formation of growth twins [38]. Consistent with the Cu LMM analysis, a few $\mathrm{Cu}_{2} \mathrm{O}$ can be identified in TEM observation (almost all identified lattice spacing is (111) plane, $0.246 \mathrm{~nm}$ ), which, respectively, is introduced by insufficient reduction in $\mathrm{Cu}^{2+}$ species and re-oxidation of $\mathrm{Cu}$ structures. The former is the independent nascent $\mathrm{Cu}_{2} \mathrm{O}$ nanoparticles (about a few nanometers in diameter) surrounded by a large amount of residual amorphous organics (Fig. 2e), while the latter is grown on the $\mathrm{Cu}$ matrix surface with a similar orientation (about 4 nm-thick, Fig. 2f).

The $\mathrm{pH}$ value of our precursor is around 2.5 due to the presence of $\mathrm{H}^{+}$after $\mathrm{Cu}\left(\mathrm{NO}_{3}\right)_{2}$ hydrolysis. The erasing process is enabled through electrochemical corrosion of the written $\mathrm{Cu}$ pattern in this natural acid medium. To confirm this mechanism, Fig. 3a plots the polarization curves of the written patterns in $\mathrm{HNO}_{3}$ solution with a $\mathrm{pH}$ of 2.5. The $\mathrm{Cu}$ pattern is corroded to $\mathrm{Cu}^{2+}$ in $\mathrm{HNO}_{3}$ solution without the formation of passivation $\mathrm{CuO}$ layer, thereby no steep slope appears in the anodic range [39]. The patterns with different $N_{\mathrm{w}}$ have a similar corrosion potential at $0.025 \mathrm{~V}$ (vs. $\mathrm{Ag} / \mathrm{AgCl}$ ), suggesting their similar corrosion resistance. Interestingly, in the anode range the current first increases and then decreases as elevating the potential. This abnormal decrease in current is because the dissolution of $\mathrm{Cu}$ (inset image in Fig. 3a) results in the disconnection of working electrode. The potential value of the inflection points increases as the $N_{\mathrm{w}}$ grows, indicating the dissolution is positively correlated with the volume of written $\mathrm{Cu}$ pattern.

Although the external voltage load can promote the dissolution of the pattern, it is difficult to completely erase it because the increased resistance will significantly slow down the corrosion. It is found that heating in the acid precursor can accelerate the corrosion process and completely erase the written pattern. Figure $3 \mathrm{~b}$ plots the erasing time as a function of heating temperature, clearly showing a higher temperature can shorten the erasing time of pattern. At a similar temperature, the thermal erasing time increases as the $N_{\text {w }}$ grows because of the increased $\mathrm{Cu}$ pattern volume. Obviously, bulk heating of patterns in solution is a nonselective process, which can be used in erasing in large area.

In this work, we use laser irradiation to selectively erase the undesired area of the pattern. The width of the erased region is limited to about $800 \mu \mathrm{m}$ when irradiating at a defocus distance of $9 \mathrm{~mm}$ (see inset of Fig. 3c). Figure 3c plots the percentage of erased area relative to the initial patterned area at this region. The removed area increases as the number of erasing scans $\left(N_{\mathrm{e}}\right)$ increases, whereof the pattern can be fully erased after $80 N_{\mathrm{e}}$. The area of the erased region is related to the laser spot diameter, which can be decreased by reducing the defocus distance. Notably, an excessive decrease in the spot diameter with a constant laser power is inadvisable, because the increased energy input will reperform the writing process. The reintroduced $\mathrm{Cu}$ structure is easily oxidized into $\mathrm{CuO}$ because the liquid film rupture caused by the large-spot laser irradiation [40] will expose the structure to the atmosphere at high temperatures (detailed results and analysis of parametric study are in Section S4 of Supporting Information). This $\mathrm{CuO}$ also can act as the passive layer to slow down the corrosion [41], causing the erasing process is no longer applicable.

Figure $3 \mathrm{~d}$ lists the XPS spectra of the $\mathrm{Cu}$ pattern with different $N_{\mathrm{e}}$ to track its composition change during erasing. The intensity of $\mathrm{Cu} 2 \mathrm{p}_{3 / 2}$ peaks decreases as the $N_{\mathrm{e}}$ increases, confirming the dissolution of pattern. The dominant peak at $932.6 \mathrm{eV}$ is assigned to the $\mathrm{Cu}_{2} \mathrm{O}$ because a corresponding peak at around $530.7 \mathrm{eV}$ can be observed in the $\mathrm{O} 1 \mathrm{~s}$ spectrum [42]. Pure $\mathrm{Cu}$ is hard to be observed during the corrosion process because the dissolution of $\mathrm{Cu}$ first forms the absorbed $\mathrm{Cu}^{1+}$ species on the surface [43]. Laser heating of the precursor during erasing may also introduce few newly $\mathrm{Cu}_{2} \mathrm{O}$. The subpeak at $934.7 \mathrm{eV}$ may be related to the subsequent formation of soluble $\mathrm{Cu}^{2+}$ species [44]. Its 
(a)
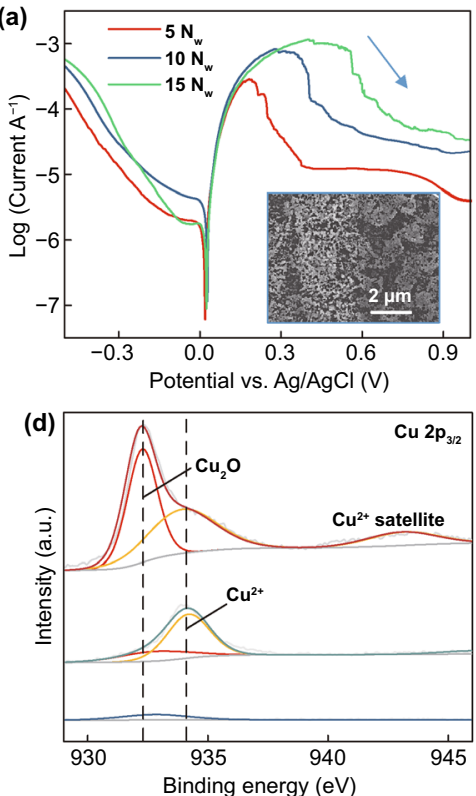

(g)

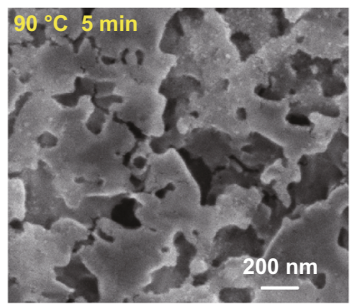

(b)

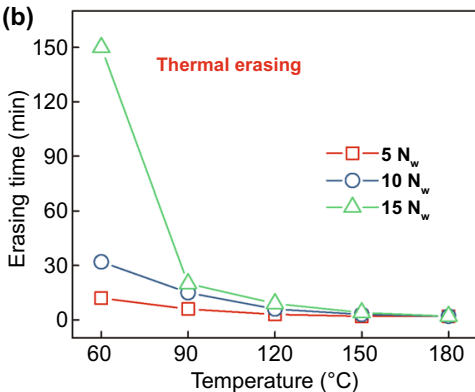

(e)
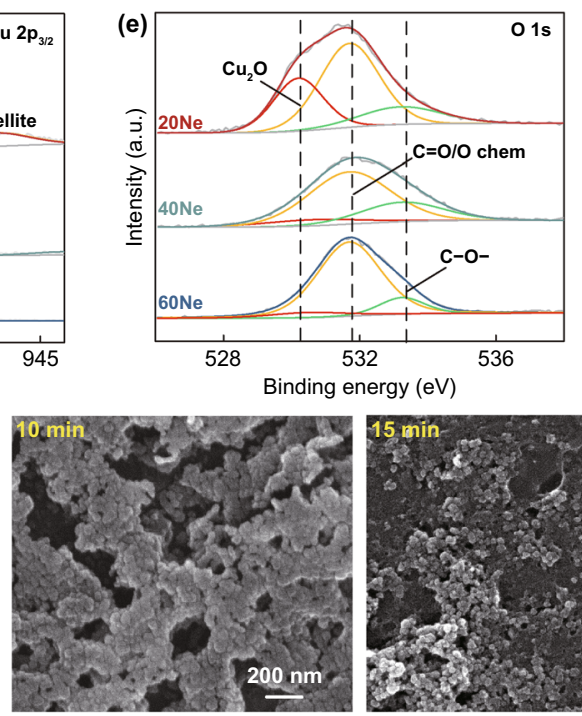
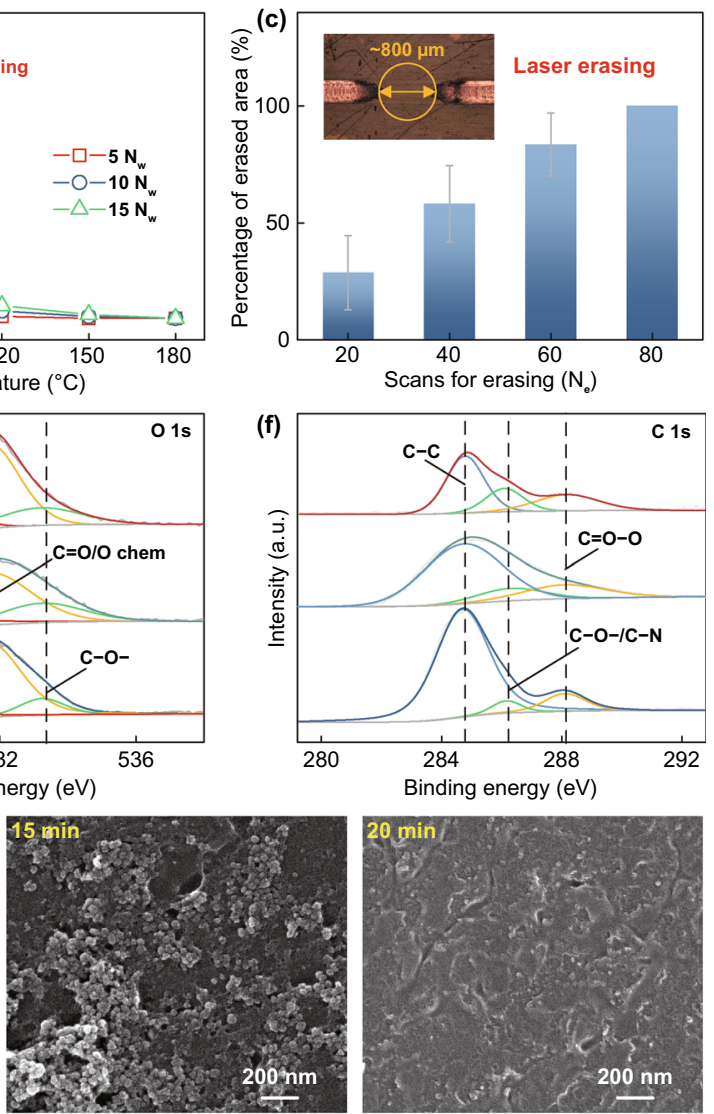

Fig. 3 Erasing mechanism and structural change. a Tafel polarization curves of the patterns obtained at different $N_{\mathrm{w}}$ in $\mathrm{HNO}_{3}$ solution $(\mathrm{pH}=2.5)$. Inset SEM image shows the morphology of the typical pattern after electrochemical test. b Erasing time of the patterns obtained at different $N_{\mathrm{w}}$ during thermal erasing with various temperatures. c Erased area percentage of the pattern obtained at $10 N_{\mathrm{w}}$ as a function of Ne. Inset shows the morphology of the pattern obtained at $10 N_{\mathrm{w}}$ with a full erasing area of about 0.25 mm ${ }^{2}$ after $80 N_{\mathrm{e}} \mathbf{d}$ Compositions of the pattern as a function of $N_{\mathrm{e}}$. e Surface morphologies change of the pattern during thermal erasing

corresponding peak located at around $531.8 \mathrm{eV}$ in the $\mathrm{O}$ $1 \mathrm{~s}$ spectrum, which coincides with the $\mathrm{C}=\mathrm{O}$ peak $[45,46]$. These results agree well with the dissolution steps of $\mathrm{Cu}$ in nitric acid, which can be described as $\mathrm{Cu}-\mathrm{e}^{-} \rightarrow \mathrm{Cu}(\mathrm{I})_{\text {ads }}$ and $\mathrm{Cu}(\mathrm{I})_{\mathrm{ads}}-\mathrm{e}^{-} \rightarrow \mathrm{Cu}$ (II) [43, 47]. The $\mathrm{C}-\mathrm{O}$ peak located at $533 \mathrm{eV}$ is also identified [48]. Both the $\mathrm{C}=\mathrm{O}$ and $\mathrm{C}-\mathrm{O}$ bonds are attributed to the presence of residual organics [49, 50], which are chemically adsorbed on the pattern surface. In the $\mathrm{C} 1 \mathrm{~s}$ spectrum, the peaks at $284.8,286$, and $288.2 \mathrm{eV}$ are, respectively, assigned to the $\mathrm{C}-\mathrm{C}, \mathrm{C}-\mathrm{O} / \mathrm{C}-\mathrm{N}$, and $\mathrm{C}=\mathrm{O}$ bonds $[51,52]$. The atomic concentration of $\mathrm{C}-\mathrm{O} / \mathrm{C}-\mathrm{N}$ and $\mathrm{C}=\mathrm{O}$ bonds decreases from 44.62 to $29.03 \%$ as the $N_{\mathrm{e}}$ increases (calculated based on their peak areas relative to that of the $\mathrm{C}-\mathrm{C}$ bond), suggesting these adsorptions decrease as the pattern dissolves. Finally, the composition at the erased region is close to the fresh PI substrate (with only $0.15 \%$ atomic concentration of $\mathrm{Cu}$ remains, see Fig. S13).

Figure $3 \mathrm{e}$ displays the typical morphologies of $\mathrm{Cu}$ pattern during the thermal erasing process to understand its microstructure change. After heating at $90^{\circ} \mathrm{C}$ for $5 \mathrm{~min}$, the dense pattern turns into a porous structure due to its partial dissolution. Nanoparticles with sintered necks are visible as the heating time increases to $10 \mathrm{~min}$. The mean diameter of these nanoparticles is $60 \mathrm{~nm}$, which closes to the grain size in TEM observation as previously shown in Fig. 2e. This indicates the intergranular corrosion occurs first during the erasing process because of a large number of defects at the grain boundary (the arrow marked in Fig. 2e). With increasing the heating time to $15 \mathrm{~min}$, the separated nanoparticles are exposed and their number decreases due to the continuous dissolution of pattern. The $\mathrm{Cu}$ nanoparticles will 
be invisible after heating for 20 min, leaving only the PI substrate present. The erased region of the substrate is slightly rougher than the fresh region (Fig. S14) because the thermal conducted from the precursor during the writing process can cause a slight ablation of the PI surface. The microstructural evolution of the pattern during the laser erasing process shows no difference with thermal erasing, excepting that the characteristics of intergranular corrosion are harder to be identified (Fig. S10). This may be because the temperature when erasing with the selected laser parameters is greater than $90{ }^{\circ} \mathrm{C}$, which introduces more adsorbed organics.

Figure 4a compares the normalized resistance of the firstwritten and rewritten $\mathrm{Cu}$ patterns. After 10 scans of rewriting $\left(N_{\text {rew }}\right)$, the average normalized resistance of the pattern slightly decreases and will remain around $90 \%$ compared to the initial one. This may be attributed to the certain roughness at the surface after erasing can provides more sites for $\mathrm{Cu}$ nucleation, thus slightly increasing the volume of $\mathrm{Cu}$ pattern [53]. The rewritten pattern can reach similar stability toward the as-written pattern. Figure $4 \mathrm{~b}$ compares the relative resistance change of these patterns during adhesion testing with $3 \mathrm{M}$ adhesive tape. The resistances of patterns are almost constant after 10 peeling cycles, indicating the excellent adhesion between pattern and substrate. Notably, this also suggests the adhesive tape can be used in thermal erasing to selectively protect and erase the patterns. By attaching $3 \mathrm{M}$ tape to the area to be retained, only the pattern that directly touched the precursor can be erased during the thermal erasing process (Fig. S15).

Figure $4 \mathrm{c}$ plots the relative resistance changes of these patterns after storing at different temperatures for 1 week. The relative resistance change of the rewritten pattern is equivalent to that of the as first-written pattern. The resistance of these patterns is almost constant when the temperature is lower than $80{ }^{\circ} \mathrm{C}\left(R / R_{0}\right.$ value at $80^{\circ} \mathrm{C}$ is only around $1.3)$, indicating their acceptable thermal stability. In bending, these patterns also have a similar relative resistance if bending radius is larger than $6 \mathrm{~mm}$ (Fig. 4d), while the rewritten pattern has a slightly higher resistance change if the radius is smaller than $5 \mathrm{~mm}$. This may be because the rewritten pattern at a similar $N_{\text {rew }}$ owns a more serious surface cracks (inset in Fig. 4d), which are easier to cause crack prorogation during bending. Reducing the $N_{\text {rew }}$ in rewriting can decrease the cracking tendency, thereby achieving a better bending performance of the pattern. For example, the $R / R_{0}$ value of the $8 N_{\text {rew }}$ pattern is about 2.9 (3.07 vs.
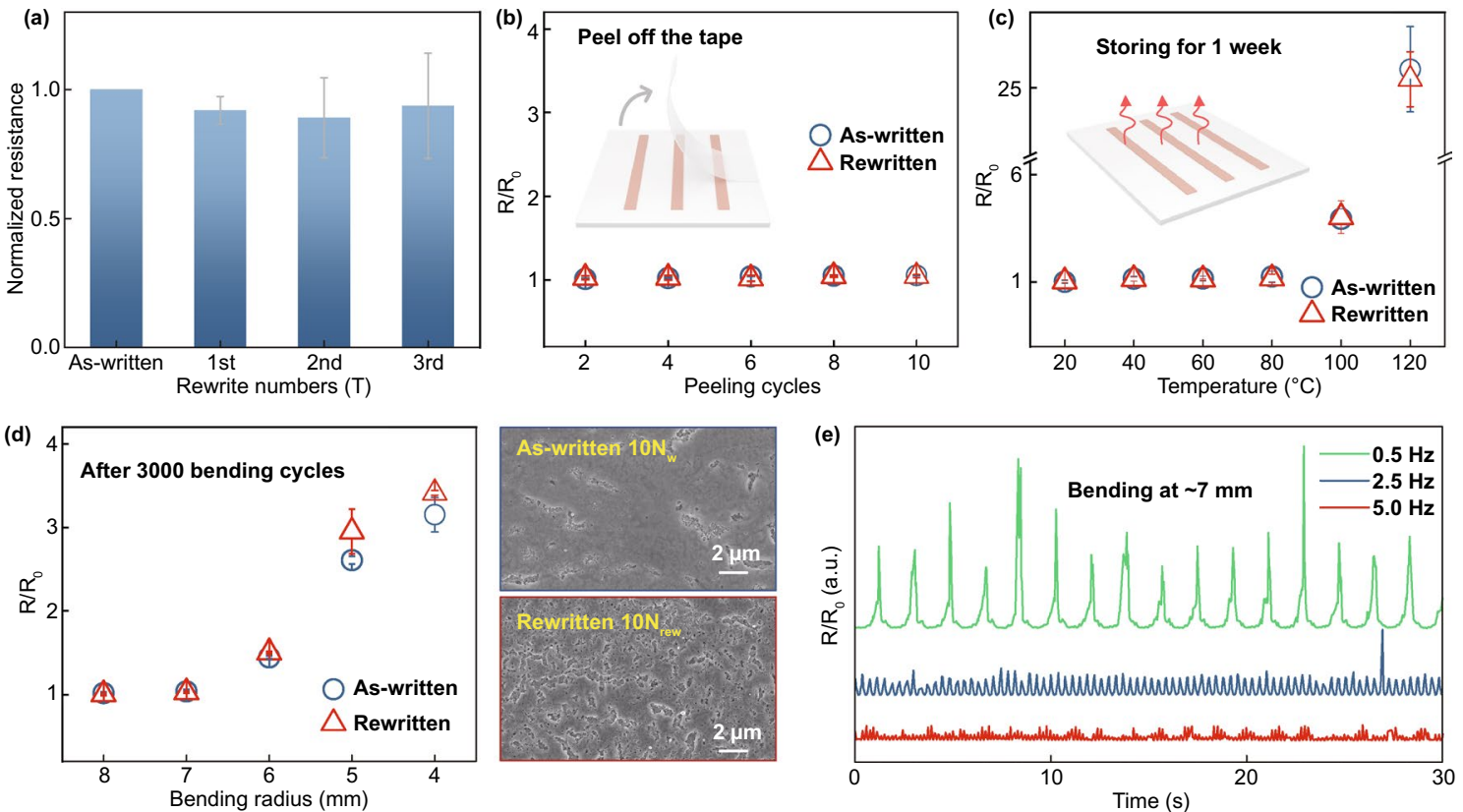

Fig. 4 Electrical performance and stability of the first-written and rewritten structures. a Normalized resistance changes of the structures as a function of rewritten numbers. Relative resistance changes of the structures after $\mathbf{b}$ adhesion testing, $\mathbf{c}$ thermal stability testing, and $\mathbf{d}$ bending testing. Insets in $\mathrm{d}$ are the surface morphologies of the as-written and rewritten patterns. Both the $N_{\mathrm{w}}$ and $N_{\text {rew }}$ are 10. e In situ relative resistance changes of the typical pattern during the bending cycles. Different in $R / R_{0}$ value is because the change rate exceeds the $0.04 \mathrm{~s}$ sampling interval 
5.93) lower than of $10 N_{\mathrm{w}}$ pattern after 2000 bending cycles at $3 \mathrm{~mm}$ radius. Notably, the relative resistance of all these patterns is nearly constant if the bending radius is larger than $6 \mathrm{~mm}$. In situ monitoring during the bending cycles indicates the resistance of patterns increases in bending state and rapidly back to the initial value in recovery (Fig. 4e), with a change period agrees with the bending frequency. The rapid response and high durability provide the pattern with a potential of servicing as the functional components in electronics, such as strain sensors. It also indicates the presented sustainable technique is suitable for the development of complex micro-electro-mechanical structures, which can be achieved by a more precise laser controlling.

This erasing-rewriting process can remove the damaged patterns and reconstruct the conductive patterns. Figure 5a plots the relative resistance changes in an as-written pattern during the enforced oxidation at $120^{\circ} \mathrm{C}$. The relative resistance of the pattern increases as the storage time increases, which reaches around 26 after 7 days. Correspondingly, the surface of the pattern exhibits an oxidized dark green color (inset in Fig. 5a). XPS analysis of the oxidized pattern indicates its surface mainly consists of $\mathrm{Cu}_{2} \mathrm{O}$ (Fig. S16), thereby it still can be converted into the $\mathrm{Cu}^{2+}$ species into solution, i.e., being erased. Similarly, the pattern resistance increases as the bending cycles grow with a bending radius of $2.8 \mathrm{~mm}$ (Fig. 5b). The relative resistance change of the pattern after 3000 bending cycles is around eight because the cracking deteriorates its conductivity. After covering with the precursor, these patterns can be erased by irradiating a defocused laser, and then consequently impose the laser rewriting process to recovery the $\mathrm{Cu}$ pattern as fresh. The resistance of the rewritten patterns is close to that of the aswritten pattern, confirming the suitability of this technology in circuit restoring.

This novel all-laser processing technology also provides a facile route for circuit modification in the manufacturing process. As shown in Fig. 5c-i, two parallel patterns are first written on the substrate to connect the external anode and cathode. Then, the regions where being required to place the electronic components can be removed by selective laser erasing process. A typical parallel circuit is obtained after placing two light-emitting diodes (LEDs) on the erased
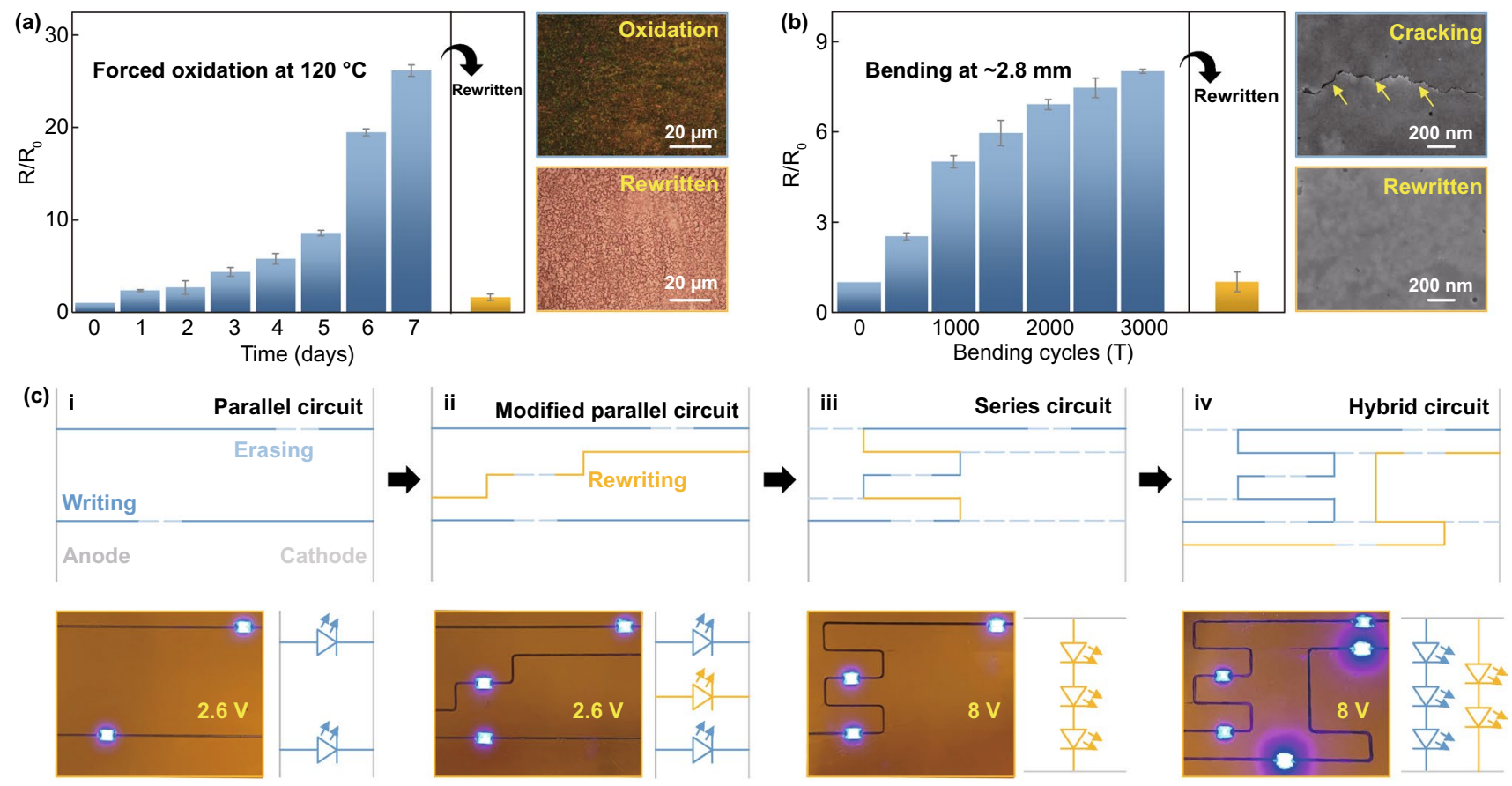

Fig. 5 Demonstration of erasable laser writing for repairing and reprogramming circuits. Relative resistance changes of the patterns during a enforced oxidation process, $\mathbf{b}$ bending process, and after rewriting. Insets are the surface morphologies of the pattern, respectively, corresponding to the state after oxidation, bending, and rewriting. $\mathbf{c}$ Schematics of pattern changes and their corresponding actual digital images for the reprogrammed circuits. The subsequent circuits are gradual modifications from the first case but on different PI substrates. LEDs are introduced after finishing these circuits to confirm they are conductive 
region, which can work at a bias voltage of $2.6 \mathrm{~V}$. As shown in Fig. 5c-ii, the writing process can add an extra parallel in the circuit. When considering of changing such a parallel circuit into a series one as a proof-of-concept, the unnecessary parts of the circuit can be removed through the laser erasing process. Together with the rewriting process, a series circuit is fabricated successfully as shown in Fig. 5c-iii. Lighting up these series connected LEDs requires the bias voltage to be increased to $8 \mathrm{~V}$. Owing to the fully removed original circuit, the erased region also can be rewritten with a new pattern to modify it into a complex one (Fig. 5c-iv). Here, the voltage distribution of a single LED on the two branches is not equal, resulting in a difference in their brightness.

\section{Conclusions}

In summary, we have developed an erasable laser writing technology based on an acidic ionic $\mathrm{Cu}$ salt precursor that can reversibly manufacture the highly conductive $\mathrm{Cu}$ pattern on the target substrate. During the writing process, irradiating the focused laser induces a photothermal reaction at the region close to the substrate, which can decompose the reducing agent to manufacture the conductive $\mathrm{Cu}$ pattern. Irradiating a defocused laser can cause a thermally accelerated electrochemical corrosion of the $\mathrm{Cu}$ structure in the acidic precursor, thereby dissolving the as-written or invalid pattern to achieve the laser erasing process. The laser rewriting process can then be further employed to manufacture the conductive $\mathrm{Cu}$ pattern at these erased regions because of their near-initial state. The comparable resistivity, adhesion, thermal stability, and bending performance between the aswritten and rewritten patterns verify the excellent reversibility of the proposed technology. Not only can this technology be used to manufacture and restore conductive patterns, but the proof-of-concept reprogrammable circuit also confirms its availability for dynamic adjustment of the circuit.

Acknowledgements The authors acknowledge financial support from the National Key R\&D Program of China (2017YFB1104900), the National Natural Science Foundation of China (51975033), and the Beijing Natural Science Foundation (3192020). P.P. acknowledges support from NSERC discovery grant. X.Z. thanks Z.H. (College of Chemistry and Materials Science, Northwest University) for his support on XPS testing and analyzing.

Open Access This article is licensed under a Creative Commons Attribution 4.0 International License, which permits use, sharing, adaptation, distribution and reproduction in any medium or format, as long as you give appropriate credit to the original author(s) and the source, provide a link to the Creative Commons licence, and indicate if changes were made. The images or other third party material in this article are included in the article's Creative Commons licence, unless indicated otherwise in a credit line to the material. If material is not included in the article's Creative Commons licence and your intended use is not permitted by statutory regulation or exceeds the permitted use, you will need to obtain permission directly from the copyright holder. To view a copy of this licence, visit http://creativecommons.org/licenses/by/4.0/.

Supplementary Information The online version contains supplementary material available at https://doi.org/10.1007/ s40820-021-00714-3.

\section{References}

1. X. Wang, L. Dong, H. Zhang, R. Yu, C. Pan et al., Recent progress in electronic skin. Adv. Sci. 2(10), 1500169 (2015). https://doi.org/10.1002/advs.201500169

2. A. Nathan, A. Ahnood, M.T. Cole, S. Lee, Y. Suzuki et al, in Flexible electronics: The next ubiquitous platform. Proceedings of the Ieee. 100 (Special Centennial Issue), 1486-1517 (2012). https://doi.org/10.1109/Jproc.2012.2190168

3. B. Ghosh, M.K. Ghosh, P. Parhi, P.S. Mukherjee, B.K. Mishra, Waste printed circuit boards recycling: an extensive assessment of current status. J. Clean. Prod. 94, 5-19 (2015). https:// doi.org/10.1016/j.jclepro.2015.02.024

4. A. Kamyshny, S. Magdassi, Conductive nanomaterials for $2 \mathrm{~d}$ and $3 \mathrm{~d}$ printed flexible electronics. Chem. Soc. Rev. 48(6), 1712-1740 (2019). https://doi.org/10.1039/c8cs00738a

5. Y.K. Li, X.W. Zhou, J.L. Chen, W. Guo, S. He et al., Laserpatterned copper electrodes for proximity and tactile sensors. Adv. Mater. Interfaces 7(4), 1901845 (2020). https://doi.org/ 10.1002/admi.201901845

6. J.H. Park, S. Jeong, E.J. Lee, S.S. Lee, J.Y. Seok et al., Transversally extended laser plasmonic welding for oxidation-free copper fabrication toward high-fidelity optoelectronics. Chem. Mater. 28(12), 4151-4159 (2016). https://doi.org/10.1021/acs. chemmater.6b00013

7. K.K. Kim, I. Ha, P. Won, D.G. Seo, K.J. Cho et al., Transparent wearable three-dimensional touch by self-generated multiscale structure. Nat. Commun. 10(1), 2582 (2019). https:// doi.org/10.1038/s41467-019-10736-6

8. T.G. Kim, H.J. Park, K. Woo, S. Jeong, Y. Choi et al., Enhanced oxidation-resistant $\mathrm{Cu@Ni} \mathrm{core-shell} \mathrm{nanoparticles}$ for printed flexible electrodes. ACS Appl. Mater. Interfaces 10(1), 1059-1066 (2018). https://doi.org/10.1021/acsami. $7 \mathrm{~b} 14572$

9. X. Zhou, W. Guo, Y. Zhu, P. Peng, The laser writing of highly conductive and anti-oxidative copper structures in liquid. Nanoscale 12(2), 563-571 (2020). https://doi.org/10.1039/ c9nr07248a 
10. R. Rahimi, S. Shams Es-Haghi, S. Chittiboyina, Z. Mutlu, S.A. Lelievre et al., Laser-enabled processing of stretchable electronics on a hydrolytically degradable hydrogel. Adv. Healthc. Mater. 7(16), e1800231 (2018). https://doi.org/10.1002/adhm. 201800231

11. X.W. Zhou, W. Guo, Y. Yao, R. Peng, P. Peng, Flexible nonenzymatic glucose sensing with one-step laser-fabricated $\mathrm{Cu}_{2} \mathrm{O}$ / $\mathrm{Cu}$ porous structure. Adv. Eng. Mater. 23(6), 2100192 (2021). https://doi.org/10.1002/adem.202100192

12. D.H. Ho, Q. Sun, S.Y. Kim, J.T. Han, D.H. Kim et al., Stretchable and multimodal all graphene electronic skin. Adv. Mater. 28(13), 2601-2608 (2016). https://doi.org/10.1002/adma. 201505739

13. X. Zhou, W. Guo, J. Fu, Y. Zhu, Y. Huang et al., Laser writing of cu/cu o integrated structure on flexible substrate for humidity sensing. Appl. Surface Sci. 494, 684-690 (2019). https:// doi.org/10.1016/j.apsusc.2019.07.159

14. S. Leppavuori, J. Remes, H. Moilanen, Utilisation of $\mathrm{Cu}(\mathrm{hfac})$ tmvs precursor gas in LCVD integrated circuit repair system. Appl. Surface Sci. 138, 123-129 (1999). https://doi.org/10. 1016/S0169-4332(98)00418-8

15. A. Iş1ldar, E.R. Rene, E.D. van Hullebusch, P.N.L. Lens, Electronic waste as a secondary source of critical metals: management and recovery technologies. Resour. Conserv. Recycl. 135, 296-312 (2018). https://doi.org/10.1016/j.resco nrec.2017.07.031

16. P. Kiddee, R. Naidu, M.H. Wong, Electronic waste management approaches: an overview. Waste Manag. 33(5), 12371250 (2013). https://doi.org/10.1016/j.wasman.2013.01.006

17. L. Rocchetti, A. Amato, F. Beolchini, Printed circuit board recycling: a patent review. J. Clean. Prod. 178, 814-832 (2018). https://doi.org/10.1016/j.jclepro.2018.01.076

18. F. Neubrech, X. Duan, N. Liu, Dynamic plasmonic color generation enabled by functional materials. Sci. Adv. 6(36), eabc2709 (2020). https://doi.org/10.1126/sciadv.abc2709

19. T. Jwad, M. Walker, S. Dimov, Erasing and rewriting of titanium oxide color marks using laser-induced reduction/oxidation. Appl. Surface Sci. 458, 849-854 (2018). https://doi.org/ 10.1016/j.apsusc.2018.07.152

20. N. Crespo-Monteiro, N. Destouches, L. Bois, F. Chassagneux, S. Reynaud et al., Reversible and irreversible laser microinscription on silver-containing mesoporous titania films. Adv. Mater. 22(29), 3166-3170 (2010). https://doi.org/10.1002/ adma. 201000340

21. Y. Lee, J. Kwon, J. Lim, W. Shin, S. Park et al., Digital laser micropainting for reprogrammable optoelectronic applications. Adv. Funct. Mater. 31(1), 2006854 (2020). https://doi. org/10.1002/adfm.202006854

22. M. Tsukamoto, R. Nishii, Y. Muraki, T. Shinonaga, M. Yoshida et al., Rewriting of low electrical resistance lines on $\mathrm{TiO}_{2}$ film by writing and erasing with femtosecond and CW fiber lasers. Appl. Surface Sci. 313, 730-735 (2014). https:// doi.org/10.1016/j.apsusc.2014.06.062

23. J.H. Park, S. Han, D. Kim, B.K. You, D.J. Joe et al., Plasmonic-tuned flash $\mathrm{Cu}$ nanowelding with ultrafast photochemical-reducing and interlocking on flexible plastics. Adv. Funct.
Mater. 27(29), 1701138 (2017). https://doi.org/10.1002/adfm. 201701138

24. S. Han, S. Hong, J. Yeo, D. Kim, B. Kang et al., Nanorecycling: Monolithic integration of copper and copper oxide nanowire network electrode through selective reversible photothermochemical reduction. Adv. Mater. 27(41), 6397-6403 (2015). https://doi.org/10.1002/adma.201503244

25. Z. Rasheva, L. Sorochynska, S. Grishchuk, K. Friedrich, Effect of the solvent type and polymerization conditions on the curing kinetics, thermal and viscoelastic performance of poly(amide-imide) resins. Express Polymer Lett. 9(3), 196210 (2015). https://doi.org/10.3144/expresspolymlett.2015.21

26. B. Ebin, O. Gencer, S. Gurmen, Simple preperation of $\mathrm{CuO}$ nanoparticles and submicron spheres via ultrasonic spray pyrolysis (USP). Inter. J. Mater. Res. 104(2), 199-206 (2013). https://doi.org/10.3139/146.110853

27. A.V. Rosario, E.C. Pereira, The effect of composition variables on precursor degradation and their consequence on $\mathrm{Nb}_{2} \mathrm{O}_{5}$ film properties prepared by the pecchini method. J. Sol-Gel Sci. Technol. 38(3), 233-240 (2006). https://doi.org/10.1007/ s10971-006-7997-3

28. Y.T. Chung, M.M. Ba-Abbad, A.W. Mohammad, A. Benamor, Functionalization of zinc oxide $(\mathrm{ZnO})$ nanoparticles and its effects on polysulfone-ZnO membranes. Desalin. Water Treat. 57(17), 7801-7811 (2015). https://doi.org/10.1080/19443994. 2015.1067168

29. B. Kang, S. Han, J. Kim, S. Ko, M. Yang, One-step fabrication of copper electrode by laser-induced direct local reduction and agglomeration of copper oxide nanoparticle. J. Phys. Chem. C 115(48), 23664-23670 (2011). https://doi.org/10.1021/jp205 $281 \mathrm{a}$

30. L.D. Zarzar, B.S. Swartzentruber, B.F. Donovan, P.E. Hopkins, B. Kaehr, Using laser-induced thermal voxels to pattern diverse materials at the solid-liquid interface. ACS Appl. Mater. Interfaces 8(33), 21134-21139 (2016). https://doi.org/ 10.1021/acsami.6b06625

31. M.D. Susman, Y. Feldman, A. Vaskevich, I. Rubinstein, Chemical deposition of $\mathrm{Cu}(2) \mathrm{O}$ nanocrystals with precise morphology control. ACS Nano 8(1), 162-174 (2014). https:// doi.org/10.1021/nn405891g

32. Y. Yu, L. Zhang, J. Wang, Z. Yang, M. Long et al., Preparation of hollow porous $\mathrm{Cu}_{2} \mathrm{O}$ microspheres and photocatalytic activity under visible light irradiation. Nanoscale Res. Lett. 7(1), 347 (2012). https://doi.org/10.1186/1556-276X-7-347

33. S. Bai, S. Zhang, W. Zhou, D. Ma, Y. Ma et al., Laser-assisted reduction of highly conductive circuits based on copper nitrate for flexible printed sensors. Nano-Micro Lett. 9(4), 42 (2017). https://doi.org/10.1007/s40820-017-0139-3

34. R. Křikavová, J. Vančo, Z. Trávníček, R. Buchtík, Z. Dvořák, Copper(ii) quinolinonato-7-carboxamido complexes as potent antitumor agents with broad spectra and selective effects. RSC Adv. 6(5), 3899-3909 (2016). https://doi.org/10.1039/c5ra2 $2141 \mathrm{~b}$

35. F. Cocco, B. Elsener, M. Fantauzzi, D. Atzei, A. Rossi, Nanosized surface films on brass alloys by XPS and XAES. RSC 
Adv. 6(37), 31277-31289 (2016). https://doi.org/10.1039/ c5ra23135c

36. J. Wang, N. Li, O. Anderoglu, X. Zhang, A. Misra et al., Detwinning mechanisms for growth twins in face-centered cubic metals. Acta Mater. 58(6), 2262-2270 (2010). https:// doi.org/10.1016/j.actamat.2009.12.013

37. O. Anderoglu, A. Misra, H. Wang, F. Ronning, M.F. Hundley et al., Epitaxial nanotwinned $\mathrm{Cu}$ films with high strength and high conductivity. Appl. Phys. Lett. 93(8), 083108 (2008). https://doi.org/10.1063/1.2969409

38. L. Lu, Y. Shen, X. Chen, L. Qian, K. Lu, Ultrahigh strength and high electrical conductivity in copper. Science 304(5669), 422-426 (2004). https://doi.org/10.1126/science.1092905

39. A. Zarrouk, B. Hammouti, A. Dafali, F. Bentiss, Inhibitive properties and adsorption of purpald as a corrosion inhibitor for copper in nitric acid medium. Ind. Eng. Chem. Res. 52(7), 2560-2568 (2013). https://doi.org/10.1021/ie301465k

40. H.M.J.M. Wedershoven, C.W.J. Berendsen, J.C.H. Zeegers, A.A. Darhuber, Infrared-laser-induced thermocapillary deformation and destabilization of thin liquid films on moving substrates. Phys. Rev. Appl. 3(2), 024005 (2015). https://doi.org/ 10.1103/PhysRevApplied.3.024005

41. Y. Wan, X.M. Wang, H. Sun, Y.B. Li, K. Zhang et al., Corrosion behavior of copper at elevated temperature. Int. J. Electrochem. Sci. 7(9), 7902-7914 (2012)

42. G.D. Khattak, A. Mekki, M.A. Gondal, Effect of laser irradiation on the structure and valence states of copper in $\mathrm{Cu}$ phosphate glass by xps studies. Appl. Surface Sci. 256(11), 3630-3635 (2010). https://doi.org/10.1016/j.apsusc.2009.12. 167

43. K.F. Khaled, M.A. Amin, Dry and wet lab studies for some benzotriazole derivatives as possible corrosion inhibitors for copper in 1.0m $\mathrm{HnO}_{3}$. Corros. Sci. 51(9), 2098-2106 (2009). https://doi.org/10.1016/j.corsci.2009.05.038

44. E. Cano, C.L. Torres, J.M. Bastidas, An XPS study of copper corrosion originated by formic acid vapour at $40 \%$ and $80 \%$ relative humidity. Mater. Corros. 52(9), 667-676 (2001)
45. C.-M. Chen, J.-Q. Huang, Q. Zhang, W.-Z. Gong, Q.-H. Yang et al., Annealing a graphene oxide film to produce a free standing high conductive graphene film. Carbon 50(2), 659-667 (2012). https://doi.org/10.1016/j.carbon.2011.09.022

46. Q. Zhu, X. Sun, D. Yang, J. Ma, X. Kang et al., Carbon dioxide electroreduction to $\mathrm{C} 2$ products over copper-cuprous oxide derived from electrosynthesized copper complex. Nat. Commun. 10(1), 3851 (2019). https://doi.org/10.1038/ s41467-019-11599-7

47. P. Jinturkar, Y.C. Guan, K.N. Han, Dissolution and corrosion inhibition of copper, zinc, and their alloys. Corrosion 54(2), 106-114 (1998). https://doi.org/10.5006/1.3284833

48. A. Galtayries, A. Mongiatti, P. Marcus, C. Chiavari, in Surface Characterisation of Corrosion Inhibitors on Bronzes for Artistic Casting. ed. by (2007), pp. 335-351

49. W. Jia, E. Reitz, H. Sun, B. Li, H. Zhang et al., From $\mathrm{Cu}_{2}(\mathrm{OH})_{3} \mathrm{Cl}$ to nanostructured sisal-like $\mathrm{Cu}(\mathrm{OH})_{2}$ and $\mathrm{CuO}$ : synthesis and characterization. J. Appl. Phys. 105(6), 064917 (2009). https://doi.org/10.1063/1.3097286

50. L.Q. Wu, Y.C. Li, S.Q. Li, Z.Z. Li, G.D. Tang et al., Method for estimating ionicities of oxides using o1s photoelectron spectra. AIP Adv. 5(9), 097210 (2015). https://doi.org/10. 1063/1.4931996

51. J.G. Cai, C. Lv, A. Watanabe, Laser direct writing of highperformance flexible all-solid-state carbon micro-supercapacitors for an on-chip self-powered photodetection system. Nano Energy 30, 790-800 (2016). https://doi.org/10.1016/j.nanoen. 2016.09.017

52. P. Yang, G. Wang, Z. Gao, H. Chen, Y. Wang et al., Uniform and conformal carbon nanofilms produced based on molecular layer deposition. Materials 6(12), 5602-5612 (2013). https:// doi.org/10.3390/ma6125602

53. J. Yeo, S. Hong, G. Kim, H. Lee, Y.D. Suh et al., Laserinduced hydrothermal growth of heterogeneous metal-oxide nanowire on flexible substrate by laser absorption layer design. ACS Nano 9(6), 6059-6068 (2015). https://doi.org/10.1021/ acsnano.5b01125 